\title{
Concentration and sources of polycyclic aromatic hydrocarbons in some commercial herbal drugs used for cholera treatment in southwest Nigeria
}

Sunday Adewale Akintelu ${ }^{\text {a,b }}$, Seyifunmi Charles Olugbeko ${ }^{c}$, Femi Adekunle Folorunso ${ }^{\mathrm{d}}$, Abel Kolawole Oyebamiji ${ }^{\text {b,e }}$ and Aderonke Similoluwa Folorunso ${ }^{\text {f* }}$

${ }^{a}$ Schoolof Chemistry and Chemical Engineering, Beijing Institute of Technology, Beijing, China.

${ }^{b}$ Department of Pure and Applied Chemistry, Ladoke Akintola University of Technology, Ogbomoso, Nigeria.

${ }^{c}$ Department of Agricultural Economics, Ladoke Akintola University of Technology, Ogbomoso, Nigeria.

${ }^{d}$ Department of Anatomy, Osun State University, Osogbo, Nigeria

${ }^{e}$ Department of Basic Sciences, Adeleke University, P.M.B. 250, Ede, Osun State, Nigeria.

${ }^{f}$ Department of Chemistry, Louisiana State University, Louisiana, USA

folorunsoaderonkesimi@gmail.com

Keywords: cancer risk, traditional medicine, cancer risk estimation, anti-diarrhea and toxicity The aim of this study was to investigate the cancer risk that could be incurred from the use of some anti-cholera herbal drugs sold in Southwest Nigeria. Three most popular anti-cholera herbal drugs were studied. The cancer risk estimation for the drugs at studied population ranges from 7.119 to $0.338 \times 10^{-8}$ in children, 9.563 to $0.129 \times 10^{-8}$ in preteen and 9.541 to $5.196 \times 10^{-8}$ in adult. The cancer risk estimated values are below the USEPA set value $1 \times 10^{-6}$. This established that the use of these herbal drugs might not lead to cancer if consumed at low dosage.

\section{Introduction}

Cholera remains a worldwide menace to public health. Cholera is an acute disease caused by Vibrio choleraea gram-negative bacillus with high indisposition and death [1-2].Global record shows that about 5 million infections from cholera occurs annually which claim the lives of about 150,000 affected patient [3]. Cases of persistent cholera outbreaks are very rampant in most Africa countries, cholera outbreaks in Africa has led to high fatality rates. Estimation from the cholera issues report to world health organization in the year 1970 to 2012 shows that $(46 \%)$ of the cases are from Africa. In addition, in the year 2012, the world documentation on cholera infection revealed that sub-Sahara Africa 
accounted for $71 \%$ of cholera infections and $86 \%$ deaths from cholera tragedy $[4,5]$. Nigeria is ranked third among the world nations that are confronted with cholera foci [6]. The first outbreaks of cholera in Nigeria was in between the year 1970 to 1990 . However, subsequent recurrence of cholera outbreaks has taken place times without number in Nigeria [6]. In 2010, 41,787 cases of cholera with 1,716 deaths was recorded in 18 northern states of Nigeria with $4.1 \%$ case fatality rate. The Southern metropolis of Nigeria is not left out of cholera outbreaks [7]. Diverse measures has been taken to eradicate or prevent the outbreak of cholera among which are thorough washing of hands with soap and clean water before meal, provision of chlorinated portable water for domestic and industrial use and consumption of well cooked foods[8]. Nevertheless, the search for medication to cure this infections when they emerge is vital. The emergence of multidrug-resistant of Vibrio choleraestrains and destructive opinions of people towards the use of synthetic antibiotics have led to search and development of novel antibiotics 9 [9]. The notion of the public on the effectiveness and safety of herbal drugs has led to increase rate in the use of herbal drugs as medication to cure cholera in Nigeria. The antimicrobial activity of many medicinal plant and herbal drug extracts against Vibrio choleraehas been previously stated [10-12]. The conviction of many on the safety and effectiveness level of herbal drugs compared to synthetic drugs are not always valid as pharmaceutical guidelines and scientist discoveries has shown that many herbal drugs and medicinal plants often contained some contaminant such as concentration of heavy metals, pesticide residue and polycyclic aromatic hydrocarbons (PAHs)[13,14]. Recently the contaminations of herbal drugs with substantial amount of cadmium, arsenic, mercury and some priority PAHs has been reported [15 ].The presences of these toxic substances in herbal drugs has been linked to poor storage conditions and environmental pollution of farm lands where medicinal plants are grown or processed, or during [16]. The existence of PAHs in medicinal plants and herbal drugs is an issue of great challenge that calls for proper assessment and 
monitoring. Therefore, to guide against this looming health problem, the toxicity assessment of these herbal drugs must be assess before endorsement for sales and use. The aim of this study was to determine the toxicity of some randomly selected anti-cholera herbal drugs used Nigeria.

\section{Materials and Method}

Three most popular known anti-cholera herbal drugs used in Southwest region of Nigeria were bought at different stores. The selection of these herbal drugs are due to their efficiency, readily availability and high popularity among the public. $500 \mathrm{~mL}$ bottles of each of the herbal drugs samples were used for the study. The description of the herbal drug samples are shown in (Table $1)$.

Table 1. Basic description of herbal drug samples.

\begin{tabular}{|l|l|l|l|l|l|}
\hline S/N & Product name & Same code & Claimed ingredients & Form & Dosage form \\
\hline 1 & "Evergreen Herb" & EGH & $\begin{array}{l}\text { SennaAlata } \text { stem and } \\
\text { Vemoniaamydalina stem }\end{array}$ & liquid & $\begin{array}{l}\text { OkitipupaOndo } \\
\text { State }\end{array}$ \\
\hline 2 & "Ruzu Mixture" & RZM & $\begin{array}{l}\text { Garcinia kola } \text { fruit } \\
\text { andMoringaOlifera }\end{array}$ & liquid & $\begin{array}{l}\text { Ogbomoso } \\
\text { Oyo State }\end{array}$ \\
\hline 3 & $\begin{array}{l}\text { "Fortified Herbal } \\
\text { Mixture" }\end{array}$ & FHM & $\begin{array}{l}\text { Prunus } \text { Africana bark, } \\
\text { sdansoniadigitata bark } \\
\text { andMangiferaindicabark }\end{array}$ & liquid & Osogbo \\
Osun State
\end{tabular}

Extraction of anti-cholera herbal drug measured with a measuring cylinder and was

\section{samples}

The method of [14] was adopted for the analytically grade n-hexane was added to the extraction of PAHs in the herbal drug samples. herbal drug sample in the test tube. The test tube Fifteen (15) $\mathrm{mL}$ of the herbal drug sample was containing the mixture was place on ultrasonic 
bath for 20 minutes for proper extraction. The extract was filtered, the filtrate obtained was store in clean beaker. Four (4) mL of analytically grade acetone was added to the residue in the test for ultrasonic extraction for another 20 minutes. The extract was filtered and the filtrate obtained was added to the filtrate in the beaker. This procedure was repeated thrice for all the samples. The filtrate was concentrated on a rotary evaporator to obtain a crude extract by removing the extracting solvent. The crude extract obtained was transferred into a cleaned sample bottle and store in the refrigerator for further purification and analysis.

\section{Clean-up of the extract.}

Column chromatography was used to purify the extract to remove any form of impurities that might been extracted alongside with the PAHs. One (1) cm wide column was packed with a mixture of aluminum oxide and silica gel in ratio $1: 3$ acting as the stationary phase using dry method of packing a chromatographic column. The crude extract was loaded on the packed column. The combination of $n$-hexane and acetone at various volume was used as used as a mobile phase for eluting the extract. The eluent obtained was air dried at room temperature to remove the eluting solvents. The obtained eluate was analyzed with Gas Chromatography-Flame Ionization Detector (GC-FID) to quantify the PAHs in the herbal drug samples. Triplicate analysis were performed on each of the purified extract.

\section{Chromatographic conditions for (GC-FID) Operation}

The operating instructions of the gas chromatography (GC) coupled with a flame ionization detector (FID) was adhere to as stated in the GC- FID using a dimethylpolysiloxane OV-5-fused silica capillary column $(30 \mathrm{~m} \times 0.25$ $\mathrm{mm}$ i.d. $\times 0.25 \mu \mathrm{m}$ film thickness) nitrogen gas was used as the carrier gas at a flow rate of 1.2 $\mathrm{ml} / \mathrm{min}$, wavelength was $200 \mathrm{~nm}$, temperature of column was $45^{\circ} \mathrm{C}$, volume of extract injected $=2$ $\mu \mathrm{l}$; column thickness was 1 meter and the detector temperature was $280^{\circ} \mathrm{C}$.

Calculation of the concentration of

Benzo(a)pyrene toxicity equivalent in the anti-diarrhea herbal drug sample 
The carcinogenic effects associated with a long

time exposure to the herbal drugs was estimated by calculating the standard lifetime risk from the concentration of PAHs in the samples with the [16] model. Consequently upon this equivalent benzo(a)pyrene toxicity was calculated.

\section{Estimation of toxic equivalent}

\section{Benzo(a)Pyrene concentration}

The model developed by $[14,16]$ was used to calculate $\mathrm{B}[\mathrm{a}] \mathrm{P}$ equivalent from the

concentrations of carcinogenic PAHs in the samples

$\mathrm{TEQ}=\Sigma(\mathrm{PAHi} \times \mathrm{TEFi})$

\section{Equation 1}

TEQ $=$ Toxicity equivalence.

PAHi $=$ Concentration of carcinogenic PAHs in each sample

$\mathrm{TEFi}=$ Toxic equivalent factor (potency relative to benzo(a)pyrene)

TEF values as stated by USEPA for benzo[a]anthracene, chrysene, benzo[b]fluoranthene, benzo[k]fluoranthene, benzo[a]pyrene, dibenzo[a,h]anthraceme and indeno[1,2,3-c,d]pyrene are $0.1,0.001,0.1,0.01$, 1,1 , and 0.1 respectively [17].

\section{Daily Exposure}

The ATSDR equation was modified to determine the health risk linked with exposure to carcinogenic PAHs in the herbal drugs samples by calculating the daily exposure dose [18].

Exposure dose $=\underline{(\text { Concentration } \times \text { intake rate } \times}$ conversion factor $\times$ exposure factor) equation 2

body

Weight of the

Dose $=$ estimated exposure dose in $(\mathrm{mg} / \mathrm{kg} /$ day $)$; Intake rate $=$ volume of sample consumed which is $0.30 \mathrm{~L}$ per day;

Body weight of consumer (children, preteens and adults $)=19 \mathrm{~kg}, 48 \mathrm{~kg}$ and $65 \mathrm{~kg}$ respectively

Conversion factor $=10^{-6}$

Exposure factor $=(6$ times a week per year $=$

$312 / 365)$

Concentration $=$ concentration of total toxicity equivalent of benzo(a)pyrene.

\section{Cancer risk evaluation}

The lifetime cancer risk was calculate using equation 3 ref [14]

Cancer risk estimation $=($ Exposure dose $\times$ Number of year of sample usage $\times$ CPF) equation 3 Average life time of user

$\mathrm{CPF}=$ cancer potency factor which is given as (7.3) 
Years of sample intake $=30$ years;

User's life time $=55$ years.

\section{Results and discussion}

Concentrations of PAHs in the anti-cholera herbal drug sample

The concentration of sixteen (16) individual PAHs in the herbal drug samples analyzed is shown in (Table 2). Among the analyzed anticholera herbal drugs, BgP had highest concentration of $5.402 \mathrm{mg} / \mathrm{kg}$ while PYR had the lowest concentration of individual PAH (0.111 $\mathrm{mg} / \mathrm{kg}$ ). The highest concentration of total PAHs in the herbal drug samples was found in FHM sample with a concentration of $(29.524 \mathrm{mg} / \mathrm{kg})$ and lowest concentration of total PAHs (15.696 $\mathrm{mg} / \mathrm{kg}$ ) was detected in RZM herbal drug sample. The percentage of carcinogenic PAHs found in the herbal drug samples was in the range of 59.81 to $53.68 \%$. Sample FHM had highest percentage of cariogenic PAHs and sample RZM had lowest percentage. The high percentages of carcinogenic PAHs observed in this study was due to high concentration of carcinogenic PAHs in the samples. The presence of PAHs in these herbal drug samples might have emanated from deposition of PAHs on the medicinal plant's parts or during the combustion of the plants parts in the cause of the herbal drugs production [19]. The concentration of total PAHs in this study was found lower than that report by [20] on some herbal teas produced in Polish which ranges from $112.43 \mu \mathrm{g} / \mathrm{kg}$ to $58.52 \mu \mathrm{g} / \mathrm{kg}$. However, short time usage and low dosage of these drugs are recommended to prevent future health challenges.

\section{Diagnostic indices of PAHs in the anti-cholera herbal drug samples}

The concentration of PAHs ratios calculated from the diagnostic indices via the modification of [22] model was employed in determination of the sources of PAHs in the herbal drug samples. The concentration of PHE/ANT ratio calculated for all the herbal drug samples were below 10 The PAHs ratio ANT/(ANT+ PHE) calculated in this study were greater than 0.1 . FLT/(FLT+ PYR) ratio in the herbal drugs were above 0.4 as showed in (Table 3). The values of ratio obtained from this calculation in an indication that the PAHs in these herbal drugs are from pyrogenic source. 
This is a confirmation that herbal drugs samples were expose to combustion in the process of production.

\section{Ring distribution of PAHs in the anti-cholera} herbal drug samples.

The number of fused rings in the PAHs structure was used to investigate the preliminary toxicity of the herbal drugs. PAHs with 2fused rings are tagged Low molecular weight PAHs (LMWPAHs), those with 3-4 fused rings are tagged moderate molecular weight PAHs (MMW PAHs) while PAHs with more than 5 fused ring are classified high molecular weight PAHs (HMWPAHs) . This classification was based on the previous study [23]. The increasing order of the concentration of PAHs according to the group distribution of PAHs in the anti-cholera herbal drugs was LMWPAHs $<$ MMWPAHs $<$ HMWPAHs for all the samples as showed in (Figure 1). PAHs with heavy molecular weight have high carcinogenic properties compared to light molecular weight PAHs [23]. This suggest that the herbal drug samples possess high carcinogenic properties due to high concentration of heavy molecular weight
PAHs found in them. Users are therefore warn to adhere to low dosage usage of these herbal drugs as high dosage and longtime usage might cause cancer or other health problems.

The benzo[a]pyrene equivalents in this study are 4.4954, 3.3075 and 6.0734 for samples EGH, RZM and FHM respectively as showed in (Table 4). FHM had highest value of TEQ benzo[a]pyrene concentration while sample RZM had lowest concentration. Subsequently upon this, the calculated TEQ and carcinogenic slope factor (CSF) was used as framework to calculate the exposure dose used for the assessment of the cancer risk incurred from the usage or exposure to these herbal drugs. The cancer risk estimation among the study populace ranges from 7.119 to $0.338 \times 10^{-8}$ in children, 9.563 to $0.129 \times 10^{-8}$ in preteen and 9.541 to $5.196 \times 10^{-8}$ in adult has showed in (Figure 3). The exposure dose and estimated cancer risk illustrated in (Figure 2 and 3) respectively were lower than the recommended value $\left(1 \times 10^{-6}\right)$ to cancer as set by USEPA [24]. However, consumer who are persistently exposed to high intake of these herbal drugs could have an increased risk of having certain form of cancer. 
FRENCH-UKRAINIAN JOURNAL OF CHEMISTRY (2020, VOLUME 08, ISSUE 02)

Table 2. Concentrations of PAHs in the anti-cholera herbal drug sample

\begin{tabular}{|c|c|c|c|c|c|}
\hline \multirow[t]{2}{*}{ PAHs } & \multirow[t]{2}{*}{ STRUCTURE } & \multicolumn{4}{|c|}{ CONCENTRATIONS OF PAHs $\left(\mathrm{mgkg}^{-1}\right)$} \\
\hline & & EGH & RZM & FHM & TOTAL \\
\hline NAP & & $0.141 \pm 0.2$ & $0.431 \pm 0.2$ & $0.914 \pm 0.3$ & 1.486 \\
\hline $\mathrm{ACY}$ & & $1.444 \pm 0.1$ & BDL & $2.391 \pm 0.2$ & 3.835 \\
\hline $\mathrm{ACP}$ & & BDL & $1.048 \pm 0.1$ & $1.115 \pm 0.1$ & 2.163 \\
\hline FLR & & $1.871 \pm 0.1$ & BDL & $0.187 \pm 0.6$ & 2.058 \\
\hline PHE & & $2.134 \pm 0.4$ & $2.565 \pm 0.2$ & $0.390 \pm 0.5$ & 5.089 \\
\hline ANT & & $1.671 \pm 0.5$ & $1.333 \pm 0.9$ & $0.417 \pm 0.2$ & 3.421 \\
\hline FLT & & $0.453 \pm 0.3$ & $0.874 \pm 0.2$ & $0.719 \pm 0.3$ & 2.046 \\
\hline
\end{tabular}




\begin{tabular}{|c|c|c|c|c|}
\hline PYR & $0.111 \pm 0.3$ & $0.207 \pm 0.2$ & $0.312 \pm 0.3$ & 0.630 \\
\hline $\mathrm{BaA}$ & $1.983 \pm 0.1$ & $1.015 \pm 0.5$ & $2.054 \pm 0.2$ & 5.052 \\
\hline CHR & 2. $512 \pm 0.3$ & $0.724 \pm 0.4$ & $4.333 \pm 0.3$ & 7.569 \\
\hline $\mathrm{BbF}$ & $2.604 \pm 0.0$ & $1.951 \pm 0.1$ & $3.076 \pm 0.5$ & 7.631 \\
\hline $\mathrm{BkF}$ & $2.157 \pm 0.3$ & $0.567 \pm 0.2$ & $1.901 \pm 0.4$ & 4.625 \\
\hline $\mathrm{BaP}$ & $0.251 \pm 0.1$ & $2.286 \pm 0.3$ & $1.001 \pm 0.1$ & 3.538 \\
\hline DhA & $1.053 \pm 0.3$ & $0.171 \pm 0.1$ & $2.135 \pm 0.4$ & 3.359 \\
\hline IcP & $4.240 \pm 0.7$ & $1.712 \pm 0.3$ & $3.157 \pm 0.5$ & 9.109 \\
\hline $\mathrm{BgP}$ & $2.129 \pm 0.3$ & $0.812 \pm 0.1$ & $5.402 \pm 0.2$ & 8.343 \\
\hline
\end{tabular}




\begin{tabular}{|l|l|l|l|l|}
\hline Total PAHs & & & & \\
& 24.754 & 15.696 & 29.524 & 69.954 \\
\hline$\Sigma$ Carcinogenic PAHs & 14.8 & 8.426 & 17.657 & 40.883 \\
\hline$\%$ Carcinogenic PAHs & & & & \\
\hline
\end{tabular}

NAP $=$ Naphthalene, ACY $=$ Acenaphthylene, ACP $=$ Acenaphthene, FLR $=$ Fluorene, PHE $=$ Phanathrene, ANT $=$ Anthracene, FLT $=$ Fluoranthene, $\mathrm{PYR}=$ Pyrene, $\mathrm{BaA}=$ Benzo (a) anthracene, $\mathrm{CHR}=\mathrm{Chrysene}, \mathrm{BbF}=\mathrm{Benzo}(\mathrm{b})$ fluoranthene, $\mathrm{BkF}=\operatorname{Benzo}(\mathrm{k})$ fluoranthene, $\mathrm{BaP}=$ Benzo (a) pyrene, DhA = Dibenzo (a,h) anthracene, IcP = Indeno $(1,2,3-\mathrm{cd})$ pyrene, $\mathrm{BgP}=\mathrm{Benzo}$ (g,h,i) perylene [Carcinogenic PAHs: BaA, BbF, IcP, BkF, CHR, BaP and DhA [19,21] ] BDL-below detection limit; means $\pm \mathrm{SD}(\mathrm{n}=3)$

Table 3. Diagnostic indices of PAHs in the anti-cholera herbal drug samples

\begin{tabular}{|c|l|l|l|l|l|l|}
\hline \multirow{2}{*}{ PAH ratio } & \multicolumn{3}{|c|}{ Sample $\left(\mathrm{mgkg}^{-1}\right)$} & $\begin{array}{l}\text { Value of } \\
\text { ratio }\end{array}$ & Indication & Inference \\
& EGH & RZM & FHM & & & \\
\cline { 2 - 6 } & 1.28 & 0.00 & 0.94 & $<10$ & Pyrogenic & Pyrogenic \\
AHE & & & & $>10$ & Petrogenic & \\
\hline$\underline{\text { ANT }}$ & 0.44 & 0.34 & 0.52 & $<0.1$ & Petrogenic & Pyrogenic \\
$($ ANT+ PHE) & & & & $>0.1$ & Pyrogenic & \\
\hline$\underline{\text { FLT }}$ & 0.80 & 0.81 & 0.70 & $<0.4$ & Petrogenic & Pyrogenic \\
$($ FLT+ PYR $)$ & & & & $>0.4$ & Pyrogenic & \\
\hline
\end{tabular}

$\mathrm{PHE}=$ Phanathrene, $\mathrm{ANT}=$ Anthracene, $\mathrm{FLT}=$ Fluoranthene and $\mathrm{PYR}=$ Pyrene 


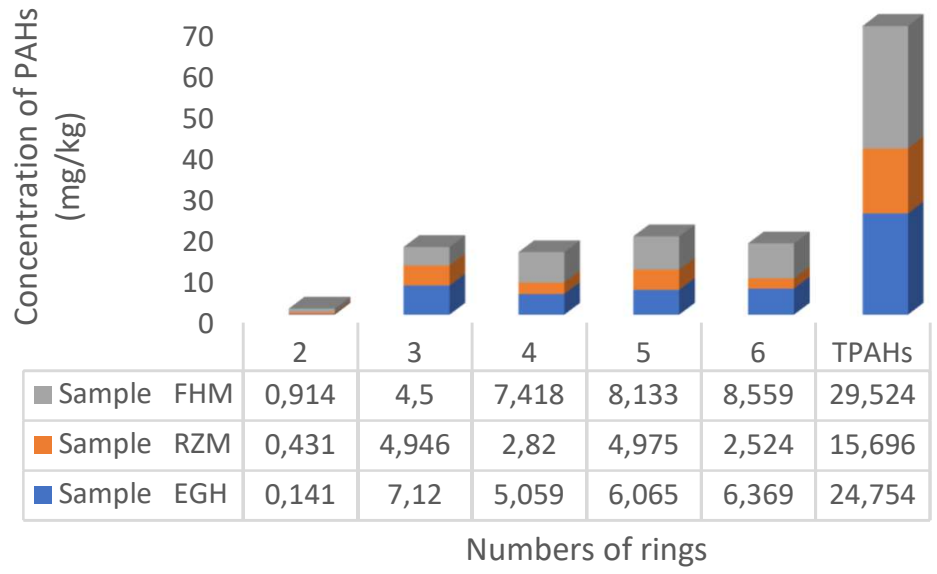

Figure 1. Group distribution of PAHs in the anti-cholera herbal drug samples

Table 4. Toxicity Equivalent (TEQ) of benzo[a]pyrene concentration $(\mathrm{mg} / \mathrm{kg})$ in anti-cholera herbal drugs

\begin{tabular}{|l|l|l|l|l|l|l|l|l|}
\hline Sample & BaA & BbF & IcP & BkF & CHR & BaP & DhA & Total Bap \\
\hline TEF & 0.1 & 0.001 & 0.1 & 0.01 & 1 & 1 & 0.1 & \\
\hline EGH & 0.1983 & 0.0026 & 0.4240 & 0.0022 & 2.512 & 1.251 & 0.1053 & 4.4954 \\
\hline RZM & 0.1015 & 0.0020 & 0.1712 & 0.0057 & 0.724 & 2.286 & 0.0171 & 3.3075 \\
\hline FHM & 0.2052 & 0.0031 & 0.3157 & 0.0019 & 4.333 & 1.001 & 0.2135 & 6.0734 \\
\hline
\end{tabular}

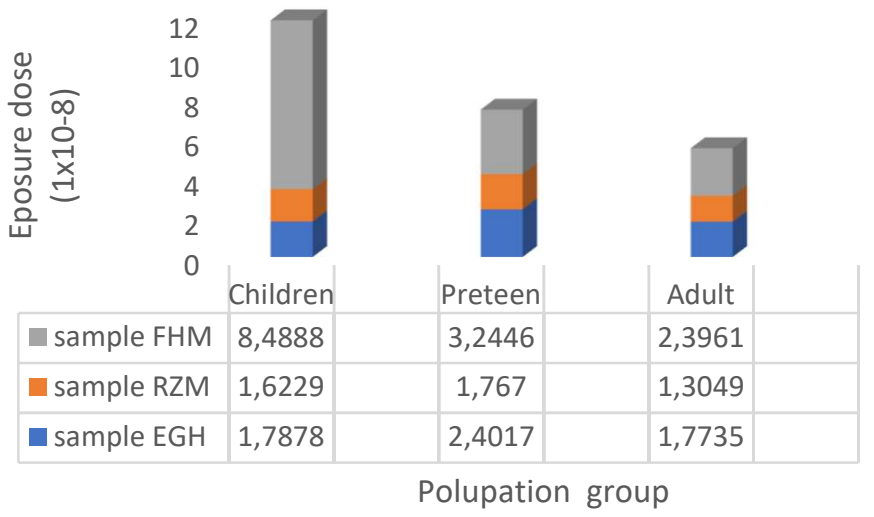

Figure 2. Exposure dose for the anti-cholera herbal drug samples 


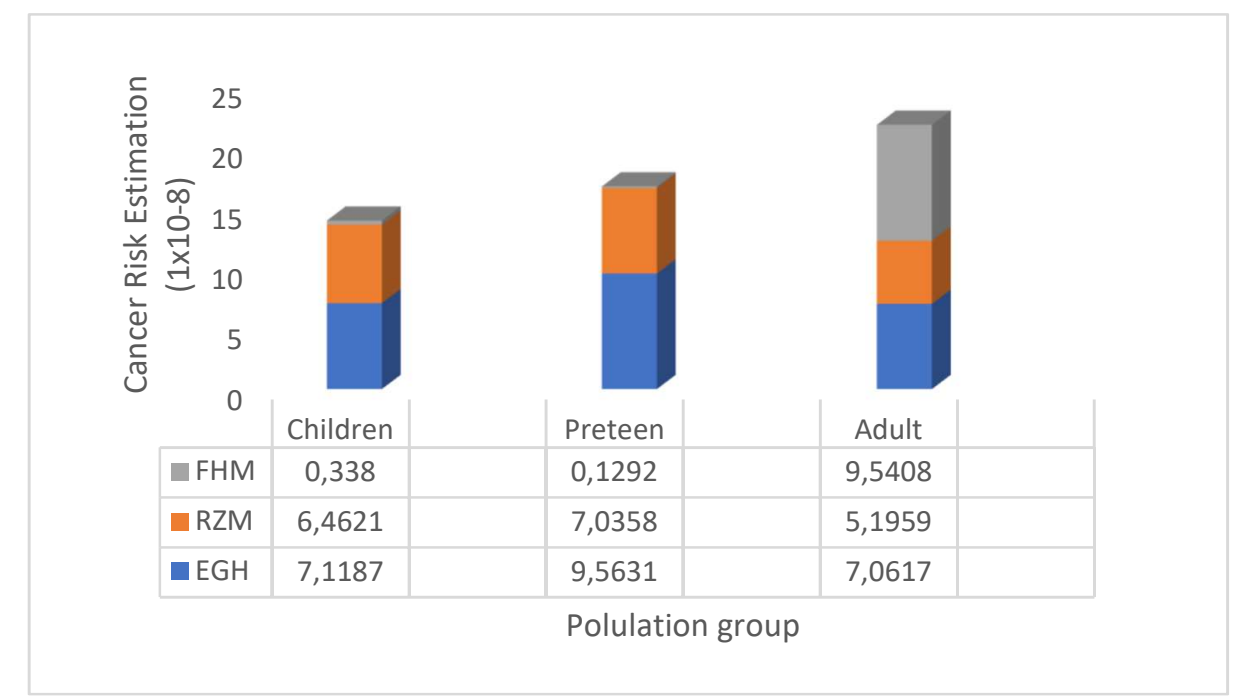

Figure 3. Estimated cancer risk for the anti-cholera herbal drug samples

\section{Conclusion}

Despite the acclaimed efficacy of the anticholera drugs studied the preliminary toxicological assessment of these herbal drugs revealed high concentration of heavy molecular weight PAHs, high concentration of carcinogenic PAHs which might lead to some health challenge. However, the cancer risk estimation among the studied populace in this study confirmed that exposure to these herbal drugs cannot produce any cancerous infections judging from the cancer risk value that is below the standard set by USEPA for carcinogenic occurrence. Low dosage and short time usage of this drugs are recommended for the public as excessive exposure can be dangerous to human health. Moreover, more scientific and pharmacological investigation, assessment and monitoring of herbal drugs should be ensured to prevent future health challenges.

\section{References}

[1] Adagbada OA, Adesida AA, Nwaokorie OF, Niemogha MT, Coker AO. Cholera epidemiology in Nigeria an overview. Pan Afr Med J. 2012; 59: 1-12.

[2] Dalhat MM, Isa NA, Nguku P, Nasir SG, Urban K, Abdulaziz M, Dankoli RS, Nsubuga P, Poggensee G. Descriptive characterization of the 2010 cholera outbreak in Nigeria. BMC Public Health. 2014; 14:1167.

[3] Dan-Nwafor C C ,Ogbonnau u, Onyiah P, Gidado S, Adebobola B, Nguku P and Nsubuga P A cholera outbreak in a rural north central Nigerian community: an unmatched case-control study BMC Public Health 2019; 19:112

[4] Mengel MA. Cholera in Africa: new momentum in fighting an old problem. Trans R Soc Trop Med Hyg. 2014; 108(7):391-2.

[5] Mengel MA, Delrieu I, Heyerdahl L, Gessner BD. Cholera outbreaks in Africa. Curr Top Microbiol Immunol. 2014; 379:117-44.

[6] Piarroux R, Faucher B. Cholera epidemics in 2010: respective roles of environment, strain changes, and human-driven dissemination. Clin. Microbiol. Infect. 2012; 18:231-8. 
[7] Ndon JA, Udo SM, William B. Vibrio-associated gastroenteritis in the lower Cross-River basin of Nigeria. $\mathrm{J}$ Clin Microbiol. 1992; 30(10):2730-2

[8] Dan-Nwafor CC , Ogbonna U, Onyiah P, Gidado S, Adebobola B, Nguku P, Nsubuga P A cholera outbreak in a rural north central Nigerian community: an unmatched casecontrol

Study BMC Public Health 2019; 19:112

[9] Galvao-Rodrigues, FF., Martins, JG., Galvao, FF, Campos, AR. Study of the interference between Plectranthus species essential oils from Brazil and aminoglycosides. Evid Based Complement Altern. Med 2013; 1-7.

[10] Sanchez, E., Heredia, N, Garcıa, S. Extracts of edible and medicinal plants damage membranes of Vibrio cholerae. Appl Environ Microbiol 2010; 76, 6888-6894.

[11] Senthilkumar, P.K. Reetha, D. Bioactivity of Cassia auriculata methanol extract against human pathogenic bacteria and fungi. Int. J. Psy. Behav. Anal. 2, 2011; 1534 1538.

[12] Taran, M, Ghasempour, H.R, Shirinpour, E. Antimicrobial activity of essential oils of Ferulago angulate subsp. carduchorum. Jundishapur J Microbiol 2010; 3, 10-14.

[13] Ekeanyanwu RC, Njoku JO, Nwodu PO, Njokuobi AE Analysis of Some Selected Toxic Heavy Metals in Some Branded Nigerian Herbal Products. J App. Pharm. Sci. 2013; 3 (4): 088-091,

[14] Akintelu AS, Abiola BE, Ajayi SO, Olabemiwo O.M. Quantification and Preliminary Estimation of Toxic Effects of Polycyclic Aromatic Hydrocarbon in Some Antimalarial Herbal Drugs in Southwest Nigeria. Bull. Pharm. Res. 2018; 8(1):152

[15] Martena MJ, Van Der Wielen JC, Rietjens IM, Klerx WN, De Groot HN, Konings EJ. Monitoring of mercury, arsenic and lead in traditional Asian herbal preparations on the Dutch Market and estimation of associated risks. US Natl. Lib. Med. Contr. Expo. Risk. 2010; 27: 190 - 205.

[16] Orisakwe OE. The role of lead and cadmium in psychiatry. North Am J Med Sci 2014; 6:370-6.
[17] Larsen JC, Larsen PB. Chemical carcinogens. In: Air Pollution and Health (Hester R, Harrison R, eds.). Cambridge, UK: The Royal Society of Chemistry, 1998; 33-56.

[18] Agency for Toxic Substance and Disease Registry (ATSDR), Public Health Assessment Guidance Manual (Update), U.S. Department of Health and Human Services, Atlanta, GA, 2005 (January).

[19] Ding X, Kamnsky LS. Human extralepaticcytoctromes P450, function in Xenobiatic in metabolism and tissue selective chemical toxicity in the respiratory and gastrointestinal tracts. Annu. Rev. Pharmacal. Toxicol. 2003; 43:149-73.

[20] Ciecierska M, Obiedziński M. The GC-MS analysis of polycyclic aromatic hydrocarbons content in selected fruit and herbal teas kerlapolica 2009; (55) 2; 19-24

[21] European Union, Commission Recommendation of 4 February 2005 on further investigation into the levels of polycyclic aromatic hydrocarbons in certain food, 2005 www:eurlex.europa.eu/LexUriServ/LexUriServ.do\%3Furi $=\mathrm{OJ}: \mathrm{L}: 2005.034: 0043: 0045: \mathrm{EN}: P D F$ [Accessed on 12-052020]

[22] Dominguez C, Sarkar SK, Bhattachrya A, Chatterjee M, Bhattacharya, BD, Jover E, Albarges J, Bayona JM, Alam AM, Satpathy KK. Quantification and Source Identification of Polycyclic Aromatic Hydrocarbons in Core Sediments from Sundarban mangrove wetland, India. Archives of Environmental Contamination and Toxicology 2010; 59(1): 49-61

[23] Lijinsky W. The formation and occurrence of polynuclear aromatic hydrocarbons associated with food. Mutat. Res., 1991; 259; 251-61.

[24] Agency for Toxic Substances and Disease Registry (ATSDR). Health Consultation, EPA FACILITY ID: OHN000510571 U.S. Department of Health and Human Services, Fostoria, Wood County, Ohio. February 2014. 